\title{
ALKALOIDS OF THE CORMS OF Colchicum
}

kesselringi i

Kh. Turdikulov, M. K. Yusupov, and A. S. Sadykov

UDC 547.944.6

The dynamics of the content of alkaloids in the corms of Colchicum kesselringii Rgl. has been reported previously [1]. Continuing a study of the phenolic part of the neutral-phenolic fraction of the alkaloids, by chromatography in a thin layer of alumina we have established the presence in it of four substances: 3-desmethyl- $\beta$-lumicolchicine $\left(\mathrm{R}_{f} 0.79\right)$, 2-desmethylcolchicine $\left(\mathrm{R}_{f} 0.36\right)$, and compounds with $\mathrm{R}_{f} 0.40$ and 0.31 [chloroform-methanol (24:1) system; revealing agent iodine vapor].

To isolate the unidentified compounds, $7.2 \mathrm{~g}$ of the mixture of phenolic alkaloids was chromatographed on a column of $140 \mathrm{~g}$ of alumina. The substances were eluted in the following sequence: $3-$ desmethyl- $\beta-$ Iumicolchicine $(0.04 \mathrm{~g})$ [eluant ether-chloroform $(1: 1)$ ] [2], the alkaloid with $\mathrm{R}_{f} 0.40(0.32 \mathrm{~g})$ [etherchloroform (1:2 and 1:4)], 2-desmethylcolchicine (4.03 g) [ether-chloroform (1:4), chloroform] [2, 3], and the alkaloid with $\mathrm{R}_{f} 0.31(0.02 \mathrm{~g}$ ) (chloroform).

The alkaloid with $\mathrm{R}_{f} 0.40$ consisted of white crystals with the composition $\mathrm{C}_{21} \mathrm{H}_{25} \mathrm{O}_{6} \mathrm{~N}, \mathrm{mp} 198-200^{\circ} \mathrm{C}$ (from ethyl acetate), $[\alpha]_{\mathrm{D}}^{20}+337^{\circ}$ (c 0.45 ; chloroform), mol. wt. 385 (mass spectrometrically); UV spectrum: 226, 264 and $344 \mathrm{~nm}$ (in methanol).

On the basis of its UV spectrum, the sign of the specific rotation $(t)$ and color reaction [4], the alkaloid with $R_{f} 0.40$ can be assigned to the $\beta$-lumi derivatives of the tropolone alkaloids. In its physicochemical constants, it resembles the alkaloid $S_{2}$ isolated by Canonica et al. [5] from the corms of the Indian plant Gloriosa superba L. The structure of the latter was establi shed by partial synthesis from 2-desmethylcolchicine and is 2-desmethyl- $\beta$-lumicolchicine. In view of the absence of an authentic sample of the alkaloid $S_{2}$, for identification we recorded the IR, NMR, and mass spectra of the alkaloid with $R_{f} 0.40$. The results obtained agree with those given in the literature [6,7] and the alkaloid does actually correspond to the structure 2-desmethyl- $\beta$-lumicolchicine.

The O-acetyl derivative of the alkaloid with $R_{f} 0.40$ has $\mathrm{mp} 222-224^{\circ} \mathrm{C}$ (from ethyl acetate and ether), $[\alpha]^{20}+352^{\circ}$ (c 1.00 ; chloroform), O-methyl derivative with $\mathrm{mp} 183-185^{\circ} \mathrm{C}$ (from ethyl acetate), identical with $\beta$-lumicolchic ine [2].

This is the first time that alkaloids have been isolated from the corms of $\mathrm{C}$. kesselringii.

\section{LITERATURE CITED}

1. M. K. Yusupov and A. S. Sadykov, Rast. Res., 5, 104 (1970).

2. F. Santavy, Alkaloids of Plants of the Genus Colchicum and Their Derivatives [in Czech], Prague (1958).

3. M. K. Yusupov and A. S. Sadykov, Dokl. Akad. Nauk UzSSR, No. 3, 25 (1967).

4. A. S. Sadykov and M. K. Yusupov, Uzb. Khim. Zh., No. 2, 38 (1960).

5. L. Canonica, B. Danieli, P. Manitto, G. Russo, and E. Bombardelli, Chem. Ind. (Milan), 49 , 1304 (1967).

6. I. M. Wilson, M. Ohashi, H. Budzikiewicz, F. Santavy, and C. Djerassi, Tetrahedron, 19, 2225 (1963).

7. V. Delaroff and P. Rathle, Bull. Soc. Chim. Fr., 1621 (1965).

V. I. Lenin Tashkent State University. Translated from Khimiya Pri rodnykh Soedineni i, No. 4, p. 541, July-August, 1971. Original article submitted March 25, 1971.

- 1973 Consultants Bureau, a division of Plenum Publishing Corporation, 227 West 17th Street, New York, N.Y. 10011. All rights reserved. This article cannot be reproduced for any purpose whatsoever without permission of the publisher. A copy of this article is available from the publisher for $\$ 15.00$. 